\title{
A PRELIMINARY STUDY OF SCRAM JET ENGINE USING STREAM THRUST ANALYSIS AND FIRST LAW AT DIFFERENT ALTITUDES
}

\author{
Venkata Hanuma Sai Teja T
}

MSc in Aerospace Engineering, Brunel University and BE in Aeronautical Engineering MVJ College of Engineering

\begin{abstract}
The SCRAM jet engine is a modification of the RAM jet engine and is capable of flying at speeds above Mach 5. In a SCRAM jet engine, the combustion takes place while the air is supersonic in nature. The purpose of the present work is to understand and model the components of a SCRAM jet engine and analyze them by the use of Thermodynamics. The First law of thermodynamics and Stream Thrust Analysis was used to determine pressure, temperature and thrust at different stations of the engine. Specific Thrust, Specific Impulse and Efficiencies were studied using both methods at altitudes O(sea level), $15 \mathrm{~km}$ and $25 \mathrm{~km}$. The assumptions, where necessary, were stated and followed. Independent parameters like cycle static temperature ratio and stream thrust were defined and studied. It was shown that the specific thrust and specific impulse increased with increase in altitude while the efficiencies decreased with altitude. A complex excel code was used to model the mathematics of the process.
\end{abstract}

Keywords: SCRAM Jet, Stream Thrust, Specific Impulse, Specific Thrust, Static Cyclic Temperature.

\section{INTRODUCTION}

A SCRAM Jet engine is an evolution of a RAM jet engine which uses the 'ram' effect to accelerate at high speeds. The combustion in a RAM jet engine happens after the intake air is decelerated to sub-sonic speeds with the use of a normal shock wave, while a SCRAM jet engine employs the use of an oblique shock and the intake air is kept supersonic while entering the combustion chamber.

Ramjet engines are primarily used in supersonic flight at Mach speed of 3-6. SCRAM jet engines can go faster than Mach 5 due to supersonic combustion. Neither SCRAM jet or Ramjet engines need to be axisymmetric due to the absence of rotating parts[7][10].

\subsection{Schematics of a SCRAM Jet Engine}

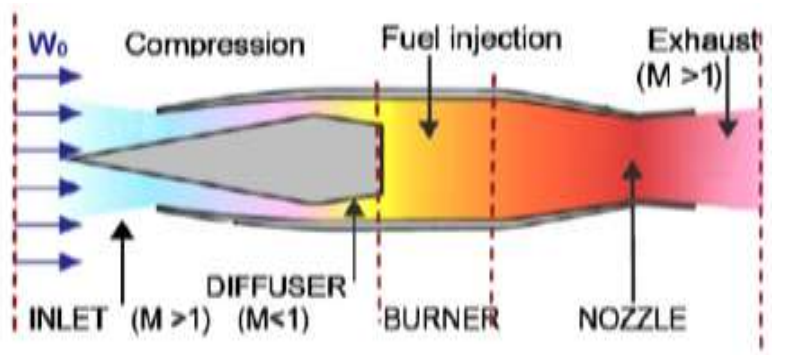

Figure 1: RAM Jet configuration [8]

The Ram jet engine can go up to Mach 6. It makes use of the 'ram' effect (compressed air) to achieve this speed. At such speeds, combustion becomes a problem. A normal shock at the end of the diffuser slows the air to below sonic speed for combustion. At speeds lower than Mach 6, this would be fine but as the speed increases, the dissociation effect increases in the combustion chamber decreasing the efficiency of combustion. In order to reduce dissociation, a SCRAM jet configuration (Supersonic Combustion RAM
Jet) is employed, here the air entering the combustion chamber is supersonic, slowed by an oblique shock at the end of the diffuser.

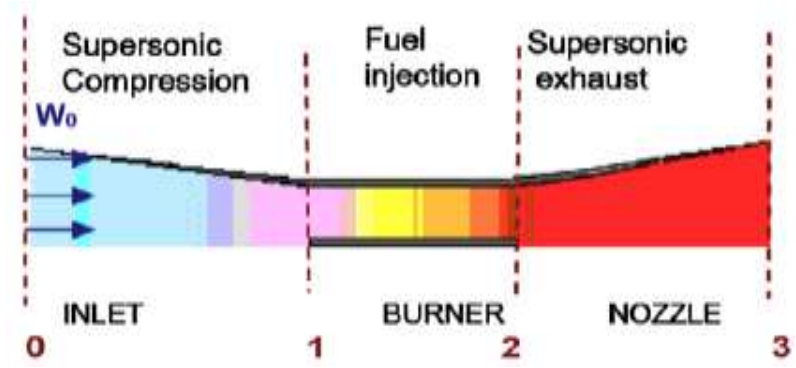

Figure-2: SCRAM Jet configuration [8]

The usual configuration of a jet engine consists of a diffuser to compressor the air, a combustion chamber to add and burn fuel and a nozzle to expand the air. This holds true for a SCRAM jet engine.

\begin{tabular}{|l|l|}
\hline \multicolumn{2}{|c|}{ Nomenclature } \\
\hline$P_{i}$ & Pressure at reference station 'i'(mPa) \\
\hline$T_{i}$ & Temperature at reference station 'i' $(\mathrm{K})$ \\
\hline$V_{i}$ & Velocity at reference station 'i' $(\mathrm{m} / \mathrm{s})$ \\
\hline$F$ & Thrust $(\mathrm{N})$ \\
\hline$m_{0}$ & Inlet mass flow rate $(\mathrm{kg} / \mathrm{s})$ \\
\hline$m_{f}$ & Fuel flow rate $(\mathrm{kg} / \mathrm{s})$ \\
\hline$g_{0}$ & Acceleration due to gravity $\left(\mathrm{m} / \mathrm{s}^{\wedge} 2\right)$ \\
\hline$I_{s p}$ & Specific Impulse $(\mathrm{s})$ \\
\hline$h_{p r}$ & Heating value of fuel $(\mathrm{kJ} / \mathrm{kg})$ \\
\hline$T_{s p}$ & Specific Thrust $(\mathrm{m} / \mathrm{s})$ \\
\hline
\end{tabular}




\begin{tabular}{|l|l|}
\hline$\eta_{0}$ & Overall efficiency \\
\hline$\eta_{p}$ & Propulsive efficiency \\
\hline$\eta_{i}$ & Efficiency of the ' $\mathrm{i}$ ' component \\
\hline$M_{i}$ & Mach number at ' $\mathrm{i}$ ' station \\
\hline$\psi$ & Cycle static temperature ratio \\
\hline$s_{i}$ & Entropy at ' $\mathrm{i}$ ' station \\
\hline$C_{P}$ & Heat Capacity $(\mathrm{kJ} / \mathrm{K})$ \\
\hline$R$ & Gas constant $(\mathrm{kJ} / \mathrm{kgK})$ \\
\hline$f$ & Stoichiometric fuel/air ratio \\
\hline$S_{a}$ & Stream Thrust Function \\
\hline
\end{tabular}

\section{Component Modelling of SCRAM Jet}

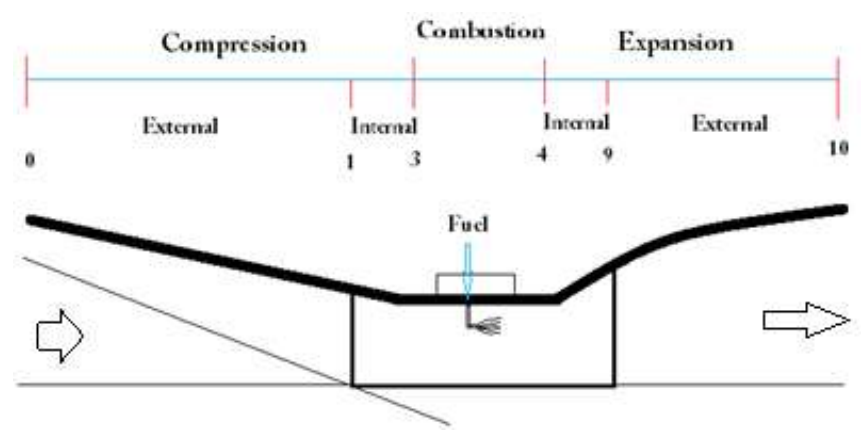

Figure 3: SCRAM Jet Engine Components

Table-1: Components of SCRAM Jet engine

\section{Reference station Engine Location}

\begin{tabular}{|cl|}
\hline $\mathbf{0}$ & Free stream Conditions \\
& External compression begins \\
\hline $\mathbf{1}$ & $\begin{array}{l}\text { External compression ends } \\
\text { Internal compression begins } \\
\text { Inlet or diffuser entry }\end{array}$ \\
\hline & Inlet or diffuser exit \\
& Internal compression ends \\
& Burner or combustor exit \\
& Burner or combustor exit \\
& Internal expansion begins \\
& Nozzle entry \\
\hline $\mathbf{4}$ & Internal expansion ends \\
& Nozzle exit \\
& External expansion begins \\
\hline & External expansion ends \\
\hline $\mathbf{1 0}$ &
\end{tabular}

The numbers mentioned in table 2 are standard for a SCRAM jet engine and have been widely used. The missing numbers in between account to additional components such as injectors, mixers etc when in use [7].

\subsection{Ideal Brayton Cycle}

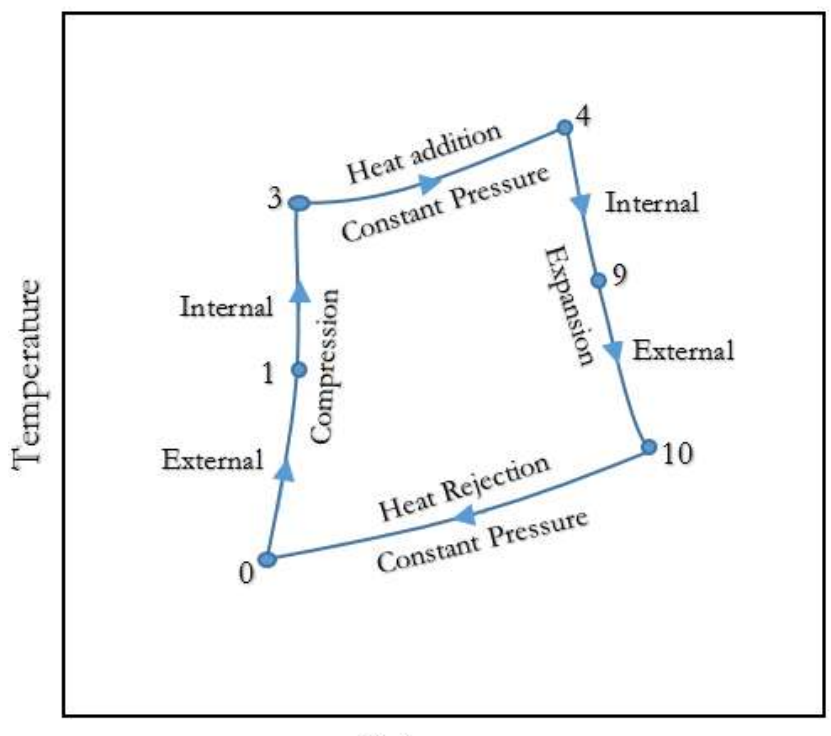

Entropy

Figure-4: Ideal Brayton Cycle[7]

Figure. 4 shows an ideal Brayton cycle. The engine is treated as a cycle and all its parameters are studied under its assumptions.

Point 0-3 represents the compression in the engine. In this work, cyclic static temperature which is the ratio of the burner entry static temperature to the freestream temperature was prioritized. The compression was taken to be adiabatic and isentropic.

Point 3-4 represents the process of heat addition. This process involved adding heat without the addition of mass and heat addition at constant pressure was studied.

Point 4-10 represents the process of expansion. This process was also considered as adiabatic and isentropic.

Point 10-0 represents the process of heat rejection. This fictional process was taken into account to maintain the equilibrium of the process. [1][5][7][8][9].

\subsection{Assumptions}

The calculations within this work were done with some assumptions, they are stated below.

(a) The working fluid was a pure substance and it was always in an equilibrium state.[7][8]

(b) The working fluid returns to its original state after the process.(Heat rejection process)[7]

(c) The whole system was treated as a control volume without any interactions with the surfaces. The system was treated as one-dimensional problem.[8]

(d) Combustion takes place only at constant pressure and dissociation effects were neglected.[8] 


\subsection{General Methodology}

The present work consists of thermodynamically analyzing a SCRAM jet engine by using the mathematical formulation of the First law of thermodynamics [7] and a concept of thrust-work potential called Stream Thrust [3].

The engine can simply be taken as an ideal Brayton cycle and performance parameters such as overall efficiency and propulsive efficiency along with other variables were studied [9]. The whole system was divided into individual components or sub-systems to analyze and optimize piecewise performance. More advanced methods such as treating the whole vehicle in terms of explicit second-law characteristics, considering the whole system as a stream tube have been studied [1]. The performance of the system in terms of thrust and propulsive losses in terms of entropy have also been studied [2].

In this work, only the First Law and Stream Thrust analysis was done using codes similar to those presented in [7] for different altitudes.

Table-2: Altitude Parameters

\begin{tabular}{|l|l|l|l|}
\hline $\begin{array}{l}\text { Altitude } \\
(\mathrm{m})\end{array}$ & $\begin{array}{l}\text { Temperature } \\
(\mathrm{K})\end{array}$ & $\begin{array}{l}\text { Pressure } \\
(\mathrm{mPa})\end{array}$ & $\begin{array}{l}\text { Density } \\
\left(\mathrm{kg} / \mathrm{m}^{\wedge} 3\right)\end{array}$ \\
\hline $\begin{array}{l}0(\text { Sea } \\
\text { Level })\end{array}$ & 288 & 101.3 & 1.225 \\
\hline 15000 & 216.55 & 12.11 & 0.195 \\
\hline 25000 & 222 & 2.55 & 0.04 \\
\hline
\end{tabular}

A complex and rigorous Excel code was developed based on the formulation and ideas presented in [7] [9].

\section{Analysis}

Some of the definitions that are employed in understanding the performance of a SCRAM jet engine are stated [7][8],

Specific Thrust - It is the ratio between uninstalled thrust and the entry mass flow rate

$$
. T_{s p}=F / m_{0}
$$

Specific Impulse - Ratio of uninstalled thrust and fuel weight flow.

$$
I_{s p}=F / g m_{f}
$$

Overall Efficiency -Ratio of thrust power to chemical energy release rate of fuel.

$$
\eta_{0}=F V_{0} / m_{f} h_{p r}
$$

Propulsive Efficiency - Ratio of the thrust power to the engine mechanical power.

$$
\eta_{p}=2 /\left(\left(V_{10} / V_{0}\right)+1\right)
$$

\subsection{First Law}

The first law of thermodynamics was used to determine the values of parameters at different stations of the engine. The parameters that were in the study are temperature, pressure and entropy. The mathematical formulation of these relations is clearly presented in [7]. An independent variable called the cyclic static temperature represents the maximum allowable compression temperature.

$$
\psi=\frac{T_{3}}{T_{0}} \geq 1
$$

The value for this limiting temperature was taken as $1580 \mathrm{~K}$ [7]. Another parameter that is co-dependent on the cyclic static temperature is the burner entry Mach number and its relation is as follows

\begin{tabular}{|c|c|c|}
\hline \multicolumn{3}{|c|}{ Input for Altitude $25 \mathrm{~km}$} \\
\hline$M_{0}$ & 6 & \\
\hline Gamma & 1.4 & \\
\hline Speed of Sound & 298.663 & $\mathrm{~m} / \mathrm{s}$ \\
\hline$V_{0}$ & 1791.978 & $\mathrm{~m} / \mathrm{s}$ \\
\hline$T_{0}$ & 222 & $\mathrm{~K}$ \\
\hline$T_{3}$ & 1580 & $\mathrm{~K}$ \\
\hline$\psi$ & 7.117117 & \\
\hline$n_{b .} f h_{P r} / C p_{0} \cdot T_{0}$ & 16.78487 & \\
\hline$n_{c}$ & 0.9 & \\
\hline$n_{b}$ & 0.9 & \\
\hline$\dot{m}_{0}$ & 300 & $\mathrm{~kg} / \mathrm{s}$ \\
\hline$n_{e}$ & 0.9 & \\
\hline$C_{p 0}$ & 1000 & $\mathrm{~J} / \mathrm{kg} \mathrm{K}$ \\
\hline$C_{p c}$ & 1090 & $\mathrm{~J} / \mathrm{kg} \mathrm{K}$ \\
\hline$C_{p b}$ & 1510 & $\mathrm{~J} / \mathrm{kg} \mathrm{K}$ \\
\hline$C_{p c} \cdot R_{e} / R_{c} \cdot C_{p e}$ & 0.722 & \\
\hline$C_{p e}$ & 1510 & $\mathrm{~J} / \mathrm{kg} \mathrm{K}$ \\
\hline$R_{c}($ air $)$ & 287 & $\mathrm{~J} / \mathrm{kg} \mathrm{K}$ \\
\hline$R_{e}($ air $)$ & 287 & $\mathrm{~J} / \mathrm{kg} \mathrm{K}$ \\
\hline$f h_{P r}$ & 4140268 & $\mathrm{~J} / \mathrm{kg}$ \\
\hline$R_{0}($ air $)$ & 287 & $\mathrm{~J} / \mathrm{kg} \mathrm{K}$ \\
\hline
\end{tabular}

$$
M_{3}=\sqrt{\frac{2}{\gamma_{c}-1}\left\{\frac{T_{0}}{T_{3}}\left(1+\frac{\gamma_{c}-1}{2} M_{0}^{2}\right)-1\right\}}
$$

These relations were set because of practical limitations [7].

Table-3: Input for Altitude $25 \mathrm{~km}$ (First Law)

\subsection{Stream Thrust}

The first law cannot account for the mass, energy fluxes within the engine, this was accounted (with assumptions) by using momentum relations and the parameter stream thrust function [7].The assumptions are as stated before. 
In its mathematical approach, the analysis averages the values of parameters such as static pressure etc. Such a case is the pressure at station 10, where the static pressure should match free stream pressure which would otherwise result in the flow being under-expanded or over-expanded.

The stream thrust function was defined as

$$
S a_{0}=V_{0}\left(1+\frac{R T_{0}}{V_{0}^{2}}\right)
$$

In this case, the specific thrust was defined as

$$
\frac{F}{\dot{m}_{0}}=(1+f) S a_{10}-S a_{0}-\frac{R_{0} T_{0}}{V_{0}}\left(\frac{A_{10}}{A_{0}}-1\right)
$$

\begin{tabular}{|c|c|c|}
\hline \multicolumn{3}{|c|}{ Input for Altitude $25 \mathrm{~km}$} \\
\hline$M$ & 6 & \\
\hline$\psi$ & 7.117 & \\
\hline$V_{0}$ & 1799.144 & $\mathrm{~m} / \mathrm{s}$ \\
\hline$n_{c}$ & 0.9 & \\
\hline$n_{b}$ & 0.9 & \\
\hline$n_{e}$ & 0.9 & \\
\hline$f h_{P r}$ & 4140268 & $\mathrm{~J} / \mathrm{kg}$ \\
\hline$T_{0}$ & 222 & K \\
\hline$R$ & 289.3 & $\mathrm{~J} / \mathrm{kg} \mathrm{K}$ \\
\hline$C_{p c}$ & 1090 & $\mathrm{~J} / \mathrm{kg} \mathrm{K}$ \\
\hline$C_{p b}$ & 1510 & $\mathrm{~J} / \mathrm{kg} \mathrm{K}$ \\
\hline$C_{p e}$ & 1510 & $\mathrm{~J} / \mathrm{kg} \mathrm{K}$ \\
\hline$\gamma_{C}$ & 1.362 & \\
\hline$\gamma_{B}$ & 1.238 & \\
\hline$\gamma_{E}$ & 1.238 & \\
\hline$P_{10} / P_{0}$ & 1 & \\
\hline$f$ & 0.0291 & \\
\hline$h f$ & 0 & \\
\hline$V_{f x} / V_{3}$ & 0 & \\
\hline$V_{f} / V_{3}$ & 0 & \\
\hline$C_{f} \cdot A_{w} / A_{3}$ & 0 & \\
\hline$T^{0}$ & 222 & $\mathrm{~K}$ \\
\hline
\end{tabular}

Table-4: Input for Altitude of $25 \mathrm{~km}$ (Stream Thrust)

\section{RESULTS AND DISCUSSIONS}

The study of parameters such as propulsive efficiency, Specific Impulse and Specific Thrust are given in the graphs.

\subsection{Propulsive Efficiency}

The First Law shows the efficiency to be the same for altitudes $15 \mathrm{~km}$ and $25 \mathrm{~km}$ while sea level efficiency is high (this is due to the availability of oxygen in the air for combustion) in graph-1

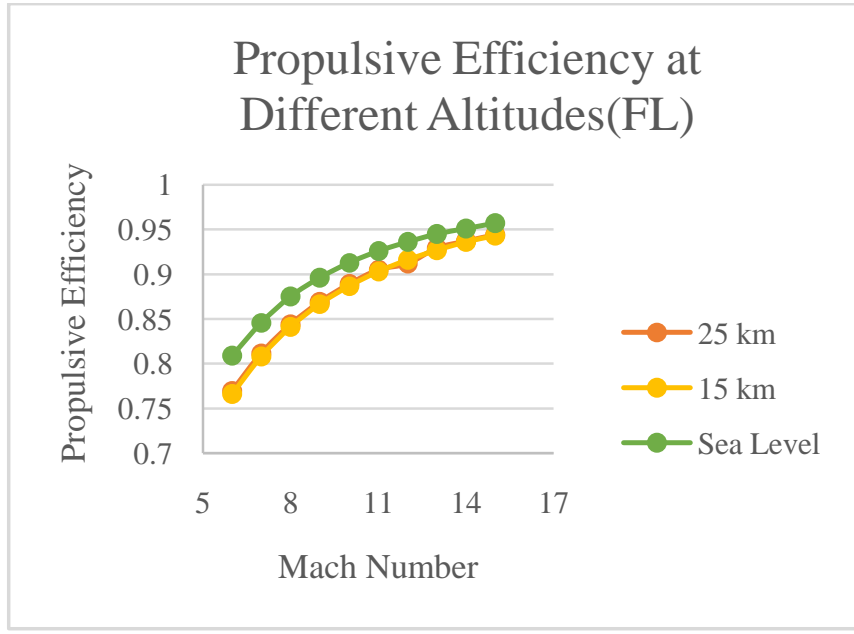

Graph-1: Propulsive Efficiency at Different Altitudes(FL)

A similar trend is seen in the graph-2 for Stream Thrust analysis. It is also seen that the propulsive efficiencies are similar for both the first law and stream thrust analysis. With the study of efficiencies, it can be said that under certain assumptions, First Law and Stream Thrust analysis provide similar results, validating the procedure.Graph-3.

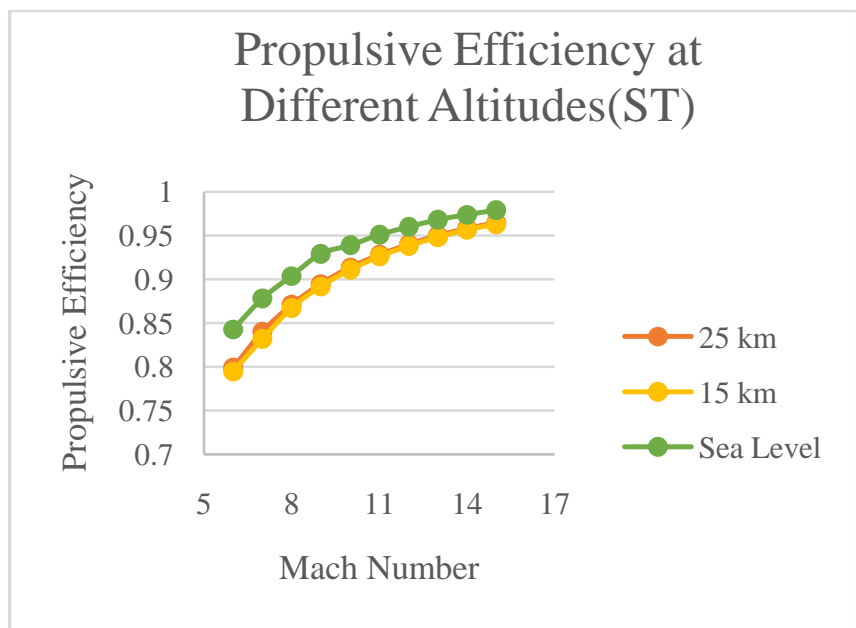

Graph-2: Propulsive Efficiency at Different Altitudes (ST)

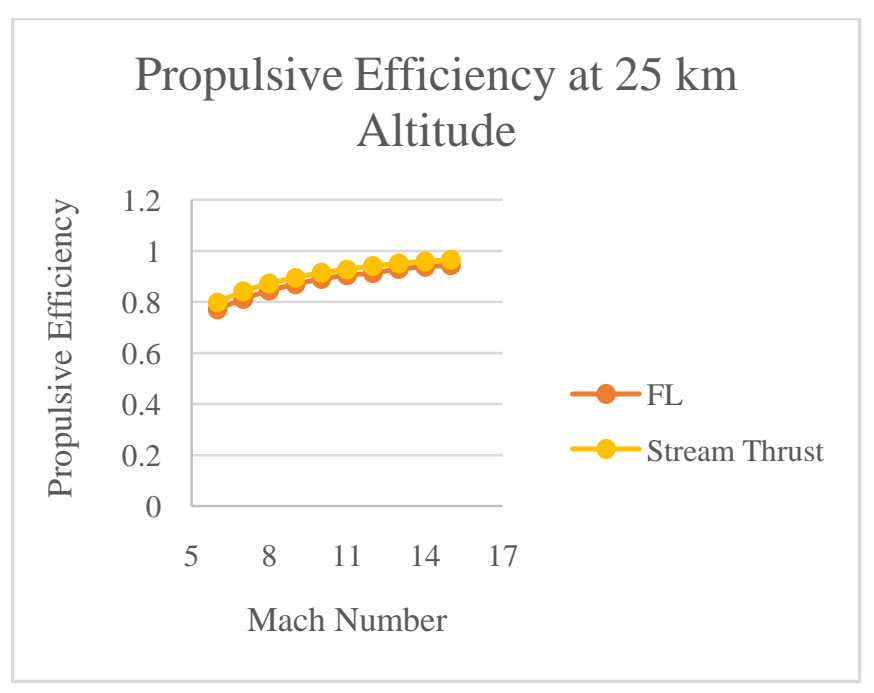

Graph-3: Comparison of First Law and Stream Thrust 


\subsection{Specific Impulse}

Although specific impulse is used to study the propulsion of rockets, it is used to here due to high speeds and the power of the engine. Graph-4 shows the specific impulse of the engine calculated using the First Law. It is seen the specific impulse is lower at sea level as opposed to propulsive efficiency. This is due to the difference in intake temperature $T_{0}$ and engine temperature at various stations. The specific impulse is similar for altitudes $15 \mathrm{~km}$ and $25 \mathrm{~km}$.

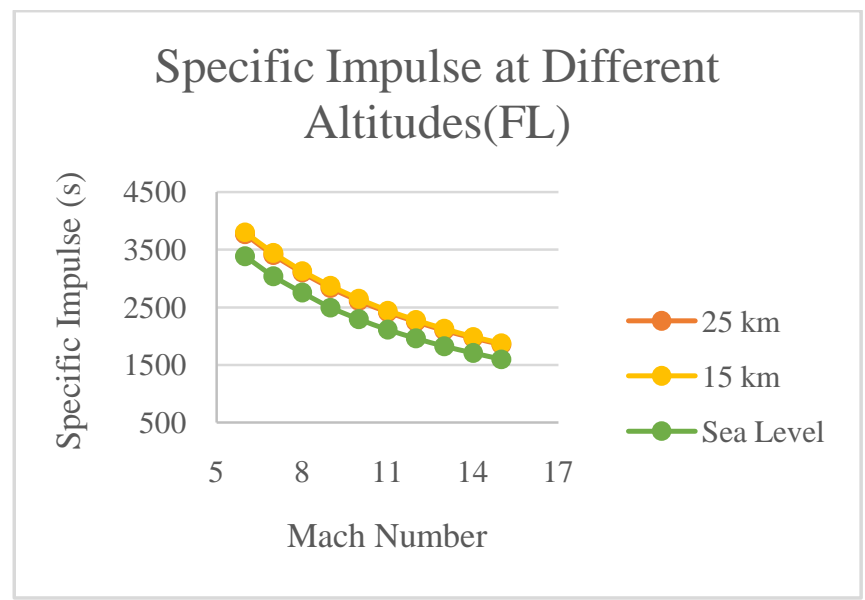

Graph-4: Specific Impulse at Different Altitudes(FL)

A similar trend is seen for specific impulse obtained through Stream Thrust Analysis show in graph-5.

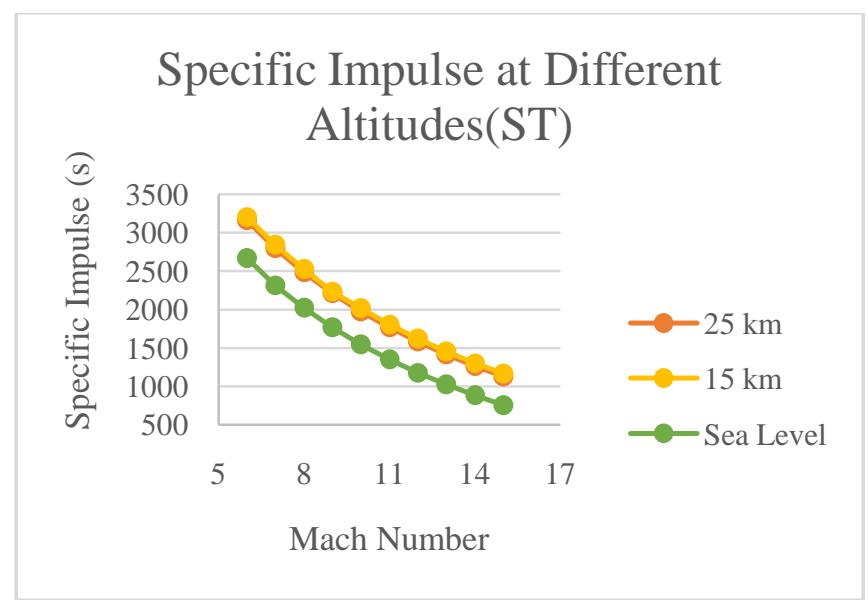

Graph-5: Specific Impulse at Different Altitudes (ST)

\subsection{Specific Thrust}

Graph-6 shows the specific thrust analyzed by the First Law at different altitudes. A trend similar to specific impulse is seen in the graph. The specific thrust is lesser in case of sea level while higher for $15 \mathrm{~km}$ and $25 \mathrm{~km}$. This is due to large differences in parameters pertaining to intake and component sections. The difference is high at higher altitudes.It can be said that drag is less at higher altitudes and the thrust depends upon drag. Graph-7 shows the specific thrust for Stream Thrust Analysis. The findings are similar to First Law.

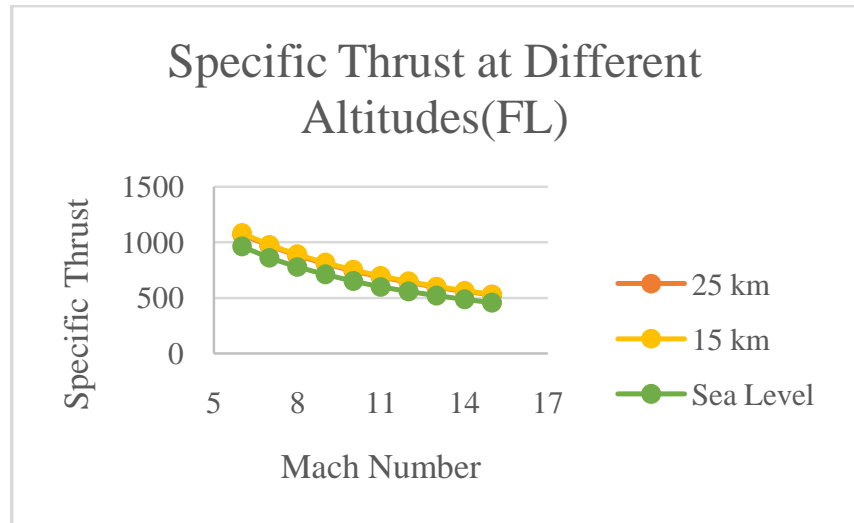

Graph-6: Specific Thrust at Different Altitudes(FL)

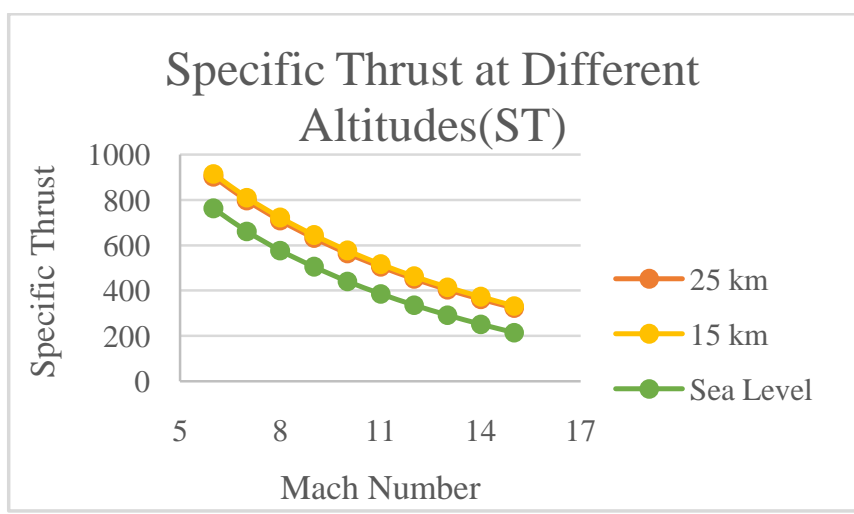

Graph-7: Specific Thrust at Different Altitudes(ST)

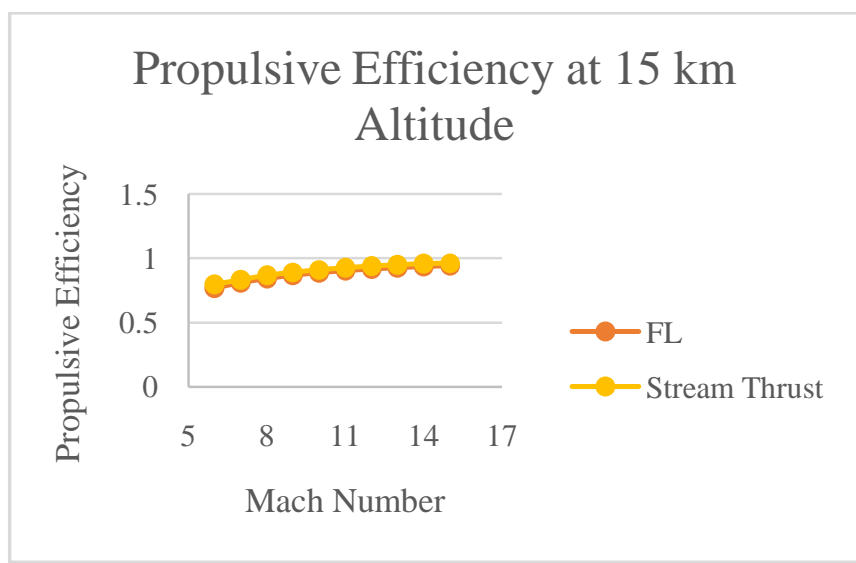

Graph-8: Propulsive Efficiency at 15 km Altitude
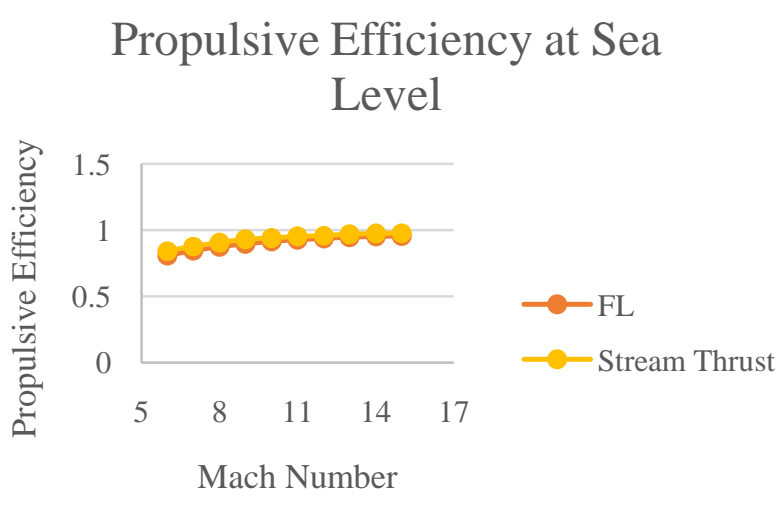

Graph-9: Propulsive Efficiency at Sea Level 


\section{CONCLUSIONS}

This work shows the study of SCRAM Jet engines by using the First Law of thermodynamics and Stream Thrust Analysis. It is seen that at altitudes higher that $15 \mathrm{~km}$, specific thrust and specific impulse are high while the opposite is true in case of propulsive efficiency. Although only propulsive efficiency was compared here, other parameters can be compared to validate both methods. But this would require an in-depth understanding of many variables that influence the process. The assumptions also play an important role. This presentation provides only a preliminary analysis, but can be developed into greater detail in future works.

\section{ACKNOWLEDGEMENT}

The author likes to thank Dr. Lionel Ganippa from Brunel University, London, for his input during the author's study.

\section{REFERENCES}

[1]. David J Riggins, T. T. D. J. M., 2006. Methodology for Performance Analysis of Aerospace Vehicle Using the Law of Thermodynamics. Journal of Aircraft.

[2]. Foa, J., 1960. Elements of Fligth Propulsion. New York: Wiley

[3]. Edward T Curran, C. R., 1973. The Use of Stream Thrust Concepts for the Approximate Evaluation of Hypersonic Ramjet Engine Performance. U.S Air Formce Aero-Propulsion Lab, Issue TR-73-38

[4]. B, R., 2001. Comparison of Thermodynamic Loss Models Suitable for Gas Turbine Propulsion. Journal of Propulsion and Power, Vol. 17, No. 2, pp. 324-332.

[5]. B, R., 2002. A Work Potential Perspective of Engine Component Performance. Journal of Propulsion and Power, Vol. 18, No.6, pp. 1183-1190.

[6]. Valentina Amati, C. B. D. S. E. S., December 2006. Development of a Novel Modular Simulation Tool for teh Exergy Analysis of a Scramjet Engine at Cruise Condition. International Journal of Thermodynamics Volume 9, pp. 111.

[7]. William H.Heiser, D. T., 1985. Hypersonic Airbreathing Propulsion. s.1.:AIAA.

[8]. Jiang Qin, W. Z. W. B. D. Y., 2010. Thermodynamic analysis and parametric study of a closed Brayton cycle thermal management system for scramjet. Internation Journal of Hydrogen Energy, pp. 356-364

[9]. Wen Bao, J. Q. W. Z. D. Y., 2009. Parametric Performance analysis of multiple Re-Cooled Cycle for hydrogen fuelled scramjet. International Journal of Hydrogen Energy, pp. 7334-7341.

[10]. Fry, R. S., 2004. A Century of Ramjet Propulsion Technology Evolution. Journal of Propulsion and Power.

\section{BIOGRAPHIES}

Venkata Hanuma Sai Teja T

Independent Researcher who received his Master's degree from Brunel University, London and Bachelors' of Engineering in Aeronautical Engineering for MVJ College of Engineering, India. Also holds a Diploma in CFD. Research interests include a broad range of CFD and FEA problems. 